Portland State University

PDXScholar

2-27-1980

\title{
Comparisons of Videotape Observation to Direct Observation
}

John W. Hanlan

Portland State University

Follow this and additional works at: https://pdxscholar.library.pdx.edu/open_access_etds

Part of the Clinical Psychology Commons, and the Speech Pathology and Audiology Commons Let us know how access to this document benefits you.

Recommended Citation

Hanlan, John W., "Comparisons of Videotape Observation to Direct Observation" (1980). Dissertations and Theses. Paper 2967.

https://doi.org/10.15760/etd.2961

This Thesis is brought to you for free and open access. It has been accepted for inclusion in Dissertations and Theses by an authorized administrator of PDXScholar. Please contact us if we can make this document more accessible: pdxscholar@pdx.edu. 
AN ABSTRACT OF THE THESIS OF John W. Hanlan for the Master of Science in Speech Communication; Emphasis Speech Pathology/Audiology presented February 27, 1980.

Title: Comparisons of Videotape Observation to Direct Observation.

APPROVED BY MEMBERS OF THE THESIS COMIITTEE:

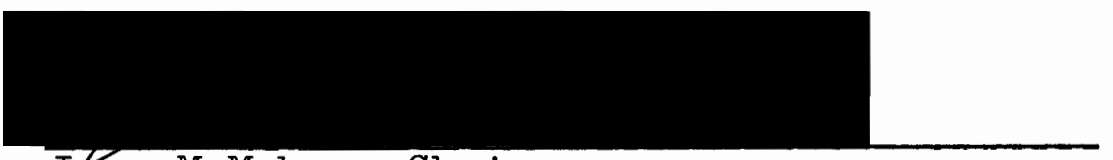

Joan McMahon, Chairperson

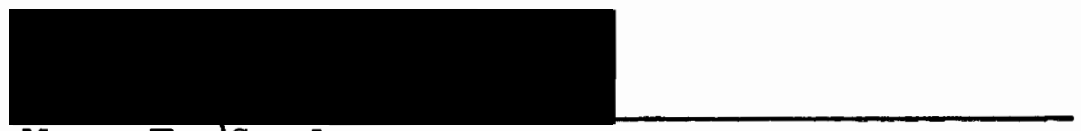

Mary E.VGordon

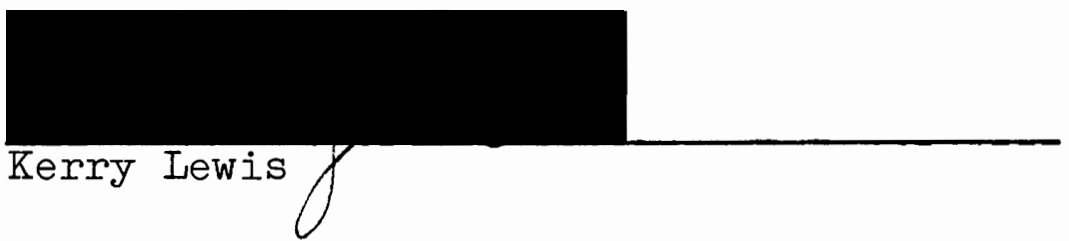

This research examined the validity of videotaped analyses of clinical sessions in comparison to direct (live) observations. The subjects were eleven student clinicians and their respective clients, enrolled Fall Term, 1979, in Portland State University's Speech and Hearing Sciences Articulation and Language and Urban Language Clinics. The Boone-Prescott Interactional Analysis System, a numerically coded system, was used to record clinician/ client interactions. Data were obtained for a randomly 
selected five-minute period from each of thirty clinical sessions.

Results of this research indicate the videotape analyses of clinical sessions correlated very highly with the direct (live) observation analyses of the same clinical sessions. This suggests the observational results are the same for videotape as for a live session. Individual behavioral category comparisons indicated two statistically significant differences at the .05 level of confidence between the two settings. Category 2 (Instruction and Model) showed that more observations were recorded for this category from the VTR method of viewing. Category 7 (Incorrect Response) indicated the observer recorded more observations using direct observation. The present research procedures do not support statements by Prather (1967), Irwin and Nickles (1970), Cooper and Thompson (1971), and Brookshire, Nicholas, Krueger, and Redmond (1978) which suggested that more information and insight can be obtained through the use of VTR observation. Results indicate one gets essentially the same results from VTR observation as from direct observation. 
COMPARISONS OF VIDEOTAPE OBSERVATION

TO DIRECT OBSERVATION

\author{
by \\ John W. Hanlan
}

A thesis submitted in partial fulfillment of the requirements for the degree of

MASTER OF SCIENCE IN SPEECH COMIUNICATION

with an emphasis in

SPEECH PATHOLOGY/AUDIOLOGY

Portland State University

1980 
TO THE OFFICE OF GRADUATE STUDIES AND RESEARCH:

The members of the Committee approve the thesis of John W. Hanlan presented February 27, 1980.
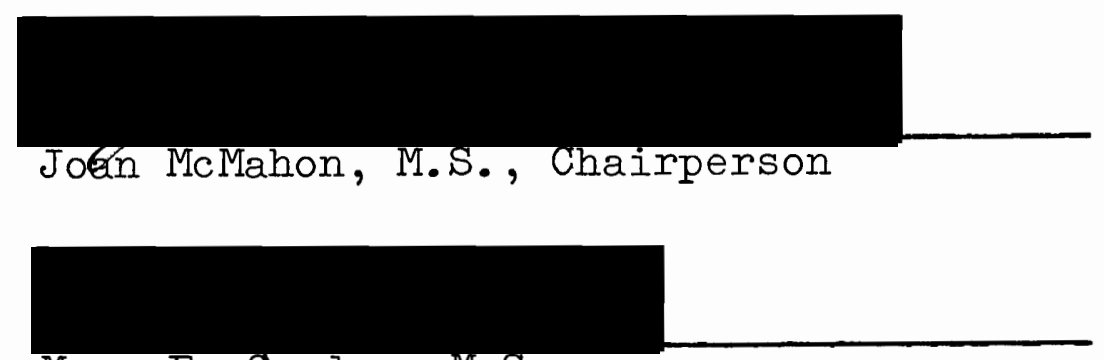
Mary E. Gordon, M.S.

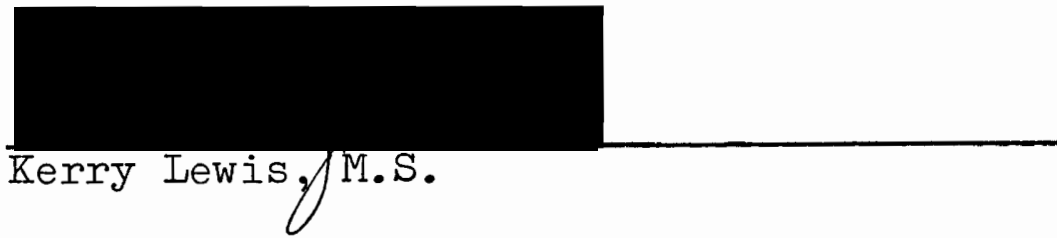

\section{APPROVED :}

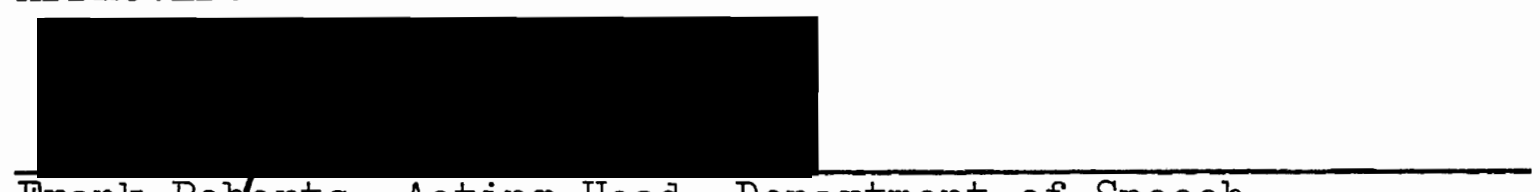

Frank Roberts, Acting Head, Department of Speech Communication

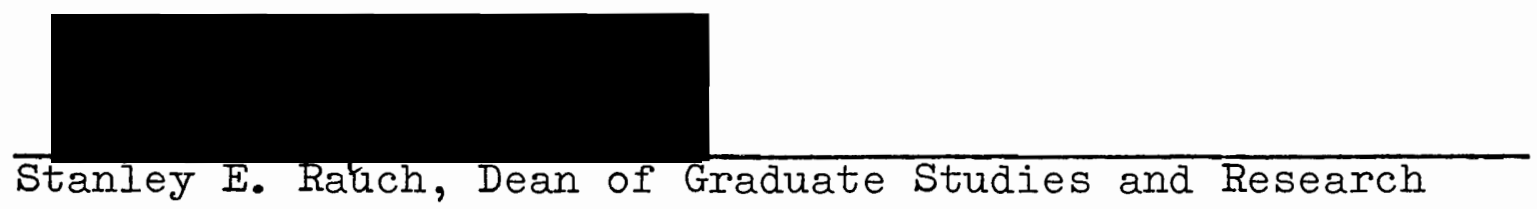


DED ICATION

TO "PETE" 


\section{ACKNOWLEDGMENTS}

These pages have no conditions and no rules. Through them I can express my thanks to the many people who helped me obtain my degree. To those of you who think one does it on their own, skip these pages. To all others, you will gain an insight into how I got through. The best way for me is to tackle the gratitude geographically. Rocky Mountain House, Alberta, Canada: To my mother, for her financial help and concerns; Aunt Daphne, special friends Sheila Moorhouse, Velma Daye, Tina McCabe, Helen Hunley, and Edna Brown--your support and encouragement really helped me get through. My other friends in Rocky, too numerous to mention, my thanks also!

Vancouver, British Columbia, Canada: Audrey and Peter Evans, Mary Lou and Bob Ambrose, Betty and Sam Bigelow who helped me through a year of sickness and three years of studies. I could always depend on a home away from home. Yellowknife, Northwest Territories, Canada: It is senseless for me to even begin to express thanks to all those who encouraged, supported, and helped me through these years. A most special thanks to my Aunt Barb--I could never have completed it without you; you will never know how much you helped. To Max, Jerry, Chris, Vicki, Stu, and Leslie--you were there whenever I needed you--thanks. 
Reimann's--Ich danke Euch: To the teachers and friends--I finally made it. Look forward to working with you again. Portland, Oregon: To Kerry Lewis, a special thanks for your input on the thesis and help in the various clinics. We had some good fireside chats over clinic problems. To Dr. Ted Grove--my statistics and I thank you for your help. To Mary Gordon--you taught me perserverance, organization, and developed in me a feeling for my own space. You have a special talent for helping students and I feel privileged to have known you. To Drs. Casteel and English--my writing style and special speech pathology information has been enriched through your teaching. To Georgie Hustead, I learned an awful lot at your side and my clients will benefit from it--thanks.

To my advisor, thesis director, and friend, Joan McMahon. If all goes according to plan you will already know what I am going to say. No one can know how much you have helped me. Those long chats as you remedied my problems-the bountiful store of knowledge which you imparted to me, your personal concern for my health, and your professionalism meant a great deal to me. I learned when and when not to open my mouth and hopefully will remember. You will always be remembered with affection. To Pat, Ed, and Shauna Hough-my home away from home and those quiet evenings with people who really became close friends--thanks for receiving me into your home. You have won a place in my heart. 
And finally to my friends at Portland State but especially to Joan and Dick Polson, Sandy and Gerry Neuburger, Carol and Dan Middleton, and Karen and Frank Mathew--you mean a lot to me and I will never forget you. Good luck in the years to come. We have come a long way since those first days. And a special thanks to Anne McGrath, wherever your acting takes you. A special friend who supported me when I originally decided to quit teaching and embark on a new career.

Bob and Marianne in Corvallis--it was reassuring to have relatives close by. Thanks for the special weekends. 
TABLE OF CONTENTS

PAGE

ACKNOWLEDGMENTS

iv

IIST OF TABLES .. . . . . . . . . . . . $\mathrm{x}$

IIST OF FIGURES . . . . . . . . . . . . . . . xi

CHAPTER

I INTRODUCTION AND PURPOSE • • • • • . • . 1

Introduction . . . . . . . . . 1

Purpose . . . . . . . . . . . 3

II REVIEW OF THE IITERATURE • • • • • • • • 4

Definition of Supervision . . . . . 4

Function of Supervision . . . . . . 5

The Clinical Supervisor . . . . . . 7

Duties of a Supervisor

Methods of Supervision . . . . . •

Evaluation of the Clinical

Practicum

Observation of Clinical

Practicum

Use of Audio and Videotape for

Observation

Feedback

Verbal Feedback

Written Feedback

Interactional Analysis Systems . . • 
Iive (Direct) Observation Vs.

Delayed VTR Observation . . . • •

Conclusions . . . . . . . 22

III METHODS . . . . . . . . . . . .

Subjects . . . . . . . . . 23

Instrumentation . . . . . . 24

Investigator . . . . . . . . 25

Investigator Training

Reliability of the Investigator

\section{Procedures}

Test Setting

Behavior Recording

Mode of Recording

Covert Observations

Overt Observation

Test Sessions

Data Analysis . . . . . . . . •

IV RESUITS AND DISCUSSION • • • • • • • • 34

Results . . . . . . . . . 34

Discussion . . . . . . . . . 38

$\mathrm{V}$ SUMMARY AND IMPLICATIONS •. •. •. • 45

Summary . • . • . . . . . . 45

Research Implications . . . . . . 46

Clinical Implications . . . . . . 48

\section{BIBLIOGRAPHY}

APPENDIX

A Boone-Prescott Content and Sequence 
B Informed Consent . . . . . . . 55

C Sample Tracking Sheet . . . . . . 57

D Ten-Category Speech and Hearing Therapy Session Scoring Form . . . . . . 58

E Omnidirectional Dynamic Microphone . . . . 60

F List of Instruments Used in the Study . . . 62 


\section{LIST OF TABLES}

TABLE

PAGE

I Order Effects of Covert/Overt Conditions . • 32

II Spearman RHO Rankings for Live and Videotaped Observations . . . . . . . . 35

III Spearman Rank-Order Correlation (RHO) of Individual Subjects . . . . . . . 36

IV Pearson Product Moment Correlation (r) . • • 37

V Two-tailed $t-T e s t$ for Dependent Means . . • 37

VI Category Ratio of Agreement Between Live and VTR . . . . . . . . . . 42

VII Total Number of Observable Results for

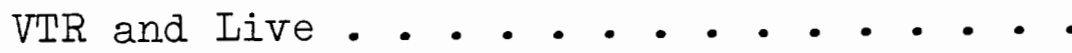




\section{LIST OF FIGURES}

F IGURE

PAGE

1. Schematic Diagram of the ObservationClinic Room Setting : . . . . . . . 28 
CHAPTER I

INTRODUCTION AND PURPOSE

\section{INTRODUCT ION}

At the annual conference in 1976, the American SpeechLanguage-Hearing Association increased the number of sessions devoted to supervisory tasks, skills, and competencies (Carnese 1977). This increase in supervisory sessions indicated a growing emphasis on the role of clinical supervisors and their supervisory tasks by those concerned with training in speech/language pathology and audiology. Reportedly a large percentage of these clinical supervisory tasks is to provide feedback concerning student skills and interactions with their clients (Haller 1967; Geoffrey 1973; Payne and Koller 1974; Culatta, Colucci, and Wiggins 1975). Traditionally evaluations of student skills have been subjective and clinical supervisors have expressed a desire for more objective methods of evaluating their students (Klevans and Volz 1974).

The expressed need for systems to objectively quantify, describe and record clinical procedures has been recognized for a number of years (Johnson 1969; Boone and Prescott 1972; Schubert, Miner, and Till 1973; Conover 1974). Boone and Goldberg (1969) and Boone and Prescott 
(1972) found that evaluating clinical procedures of management activities (interactions) between clinician/client could be enhanced by some means of systematic observation or recording of the events observed. An appropriate means for studying the observable interactions occurring between two or more people appears to be an interactional analysis of behavioral events.

Research has indicated these interactional analysis systems are useful methods for analyzing clinician/client interactions by individuals in various settings (Prescott 1970; Boone and Prescott 1972; Butler 1974). These systematic observations (interactianal analyses) have permitted the clinical supervisor and clinician to isolate, label, and analyze specific behaviors which occurred in clinical interactions. However, since this method requires direct observation by the clinical supervisor, it meant the supervisor must be available at the time when a clinical management session is taking place. As these observations require three to five minutes (Schubert and Laird 1974) of the undivided attention of the supervisor, any unforeseen interruptions of these direct observations invalidate the analysis and thus valuable time is lost. Therefore alternate methods of observation appeared to be warranted.

Several authors have suggested the use of videotaped or filmed observations of clinician/client interactions as alternative methods of observation (Schubert et al. 1973; 
Boone and Prescott 1972; Schultz 1972; Schubert and Laird 1974). Boone and Goldberg (1969) found that viewing a videotaped recording of a clinic session is a valuable method for clinical supervisors to evaluate a student's performance. However, their study did not compare videotaped sessions with directly observed sessions. If clinical management sessions could be videotaped and analyzed with the same accuracy as a direct observation, the opportunity for increased supervision may be provided. Empirical data have suggested that videotaping is both a valid and time-efficient method of supervising student clinicians; however, a review of the literature regarding the validity of analysis of videotaped sessions compared to analysis of live sessions, revealed little information.

\section{PURPOSE}

The purpose of this study was to examine the validity of videotaped analyses of clinical sessions in comparison to direct observation. More specifically, this study employed the Boone-Prescott Interactional Analysis System (Boone and Prescott 1972) (see Appendix A) and compared the analysis of the videotaped session with the analysis of the direct observation of the same interaction.

The question asked was: Are the observational results the same for videotape as for a live session? 
CHAPTER II

REVIEW OF THE LITERATURE

DEFINITION OF SUPERVISION

According to Oratio (1977) the definition of supervision can be approached through three major concepts. The first concept, function of clinical supervision, is the operation or tasks of the supervisor. More specifically, the supervisor must assist the student in developing optimum clinical skills such as establishing directions, goals, and priorities in the clinic setting. The second concept, structure of supervision, implies the arrangement of supervisory functions, i.e., it is essential that supervisors contribute materials, methods, ideas, and procedures for the use by the student in clinical management sessions. Finally, the third concept, process of supervision, involves the interaction of the supervisor and clinician. This interaction may take many forms, e.g., verbal conferences, written reports, and combinations of both. Furthermore, the function, structure, and process of supervision can be linked under a unified whole as an objective role of supervision.

Supporting these comments, Villarreal (1964) stated the role of effective supervision should transcend the mere 
monitoring of the student's clinical activities. It should include the teaching of clinical content, the demonstration and clarification of clinical techniques, and the mature counseling of the student in relation to his clinical training, including written and verbal feedback through supervisor-clinician conferences.

Supervision can thus be defined as a process of interaction between the supervisor and clinician within the aforementioned parameters of structure and function. This interaction process which takes place between the supervisor and clinician is intended to have a practical effect on the training of student speech clinicians.

\section{FUNCT ION OF SUPERVISION}

Supervision of speech pathology clinical practicums provides a means for the supervisor to change clinician behavior and facilitate the development of an autonomous clinical self (Oratio 1977). The means or vehicle provided by supervision may be varied. According to responses on student questionnaires regarding supervision, Underwood (1979) found students most often requested more direction, feedback, and planning assistance for clinical management sessions. Feedback and direction can probably be provided after supervisory observation of the clinical session, which would in turn help to make the feedback and direction pertinent to the individual student clinician. 
Observation and supervision of the clinical process are intended to have a definite purpose. In other words, it is hoped the student clinician will develop a professional, self-directing clinical sense of responsibility for both the client and supportive personnel, utilizing the comments, critiques, and suggestions of the supervisor (Oratio 1977).

The need for supervision, and direct observation is recognized by the American Speech-Ianguage-Hearing Association which specifies at least one-fourth of the student's practicum must be directly observed by a supervisor who holds a Certificate of Clinical Competence (Carnese 1977). Further, Halfond (1964) stated the supervisory process is of particular concern, since it appears to be one of the more crucial aspects of speech pathology education. Villarreal (1964) summarized the importance of clinical supervision with the following:

Clinical practicum is a critical part of the total preparation of one who would prepare himself for the evaluation and alleviation of speech and hearing disorders. Before knowledge learned from books and classroom lectures can be put to use, a considerable degree of clinical competence must be developed. For this, the speech pathologist must practice with people and he must practice under careful supervision until there is no doubt he can work independently.

The supervisory task requires the attention and observation of a clinical supervisor who must exhibit specific skills. 


\section{THE CLINICAL SUPERVISOR}

The American Speech-Language-Hearing Association (ASHA) stipulated the clinical supervisor must have the Certificate of Clinical Competence (CCC) in the area being supervised. Miner (1967) suggested further qualifications of the supervisor as a person who:

1. understands and utilizes the dynamics of human relationships which promote the growth of the student clinician.

2. establishes realistic goals, with the student clinician that are clearly understood by both student and supervisor.

3. observes and analyzes the teaching-learning act involved in the management session.

4. provides the student with feedback necessary to enable him to become increasingly self-analytical.

5. knows and uses a variety of materials, methods and techniques which are based on a sound theory, successful practice and documented research.

6. recognizes and sets aside his/her personal prejudices and biases which influence perception and develop rigidity in order that the subjective task of evaluation may become as objective as possible.

7. challenges and motivates the student clinician to strengthen his clinical competency without the supervisor's assistance.

8. appreciates the individual differences among student clinicians to such an extent that supervisory programs and practices may be radically altered to suit each student's needs.

Duties of a Supervisor

Anderson (1974) stated the duties of the clinical supervisor were to evaluate, encourage, reinforce, 
coordinate, facilitate, and moderate the clinical process. Oratio (1977) further suggested the supervisor has a responsibility to observe the clinical session and provide feedback which will: (1) effect a change in clinician behavior thus changing client behavior in a more positive direction and, (2) enable the clinician to become independent and autonomous as a professional. The supervisor who possesses the qualifications as stated by ASHA and the skills and qualities noted by Miner (1967) and who will undertake the duties and responsibilities mentioned by Anderson (1974) and Oratio (1977) provides supervision of the clinical process through a variety of methods.

\section{METHODS OF SUPERVISION}

Currently within the field of speech pathology there is no uniform practice concerning a supervisory model or process of clinical training. The philosophical differences ranging from the highly permissive to the more rigidly structured supervisors result in different supervisory procedures. For instance, the student may follow an independent situation containing conditions for continued growth and self-actualization (Ward and Webster 1965). Conversely, the student may be required to seek and take advice from an established authority (Halfond 1964). In their review of the literature, Boone and Prescott (1972) found little evidence that research has been conducted 
relative to supervisory techniques and methodologies for evaluating students' progress. However, there is a consensus from this investigator's review of available literature that generalizations in supervisory techniques do exist in one form or another. The most common generalizations in supervisory techniques appeared to be in the evaluation of the clinical process based upon observation.

\section{Evaluation of the Clinical}

\section{Practicum}

Traditionally, evaluations of the student clinicians were subjective, i.e., rating students on a list of attributes, including dependability and clinical rapport followed by lengthy written comments about their clinical interaction (Klevans and Volz 1974). Clinician comment on the supervisor's subjective evaluation was limited to what both the supervisor and clinician could remember of the clinic session. Thus any subjective aspects of the supervisor's evaluation could not very well be challenged by the student. In recent years clinical supervisors have expressed a need for more objective techniques for evaluating the clinician-client dyad (Carnese 1977). Brown (1967), Haller (1967), and Klevans and Volz (1974) developed evaluation forms which generally provide for rating clinicians' "personal characteristics, diagnostic ability, management skills and progress." This was a beginning of objective evaluations. However, the development of 
objective evaluations requires observation and critique of clinical sessions. As Anderson (1974) stated, supervisors must develop infinite skills in behavioral observation and utilize whatever means possible for an objective observation.

Observation of Clinical

Practicum

Observation and critique of clinical sessions does take place (Halfond 1964; Van Riper 1965; Kunze 1967;

Darley 1969; Boone and Prescott 1972). This observation may take the form of direct observation whereby the supervisor views the actual session as it is taking place, or through indirect observations where a videotaped replay of the session is viewed by the supervisor and/or clinician. Supervisors widely incorporated both these observational methods into their clinical practice (Boone and Prescott 1972 ).

Use of Audio and Videotape for Observation

Observing and evaluating behavior using audiotapes, audiovisual film, closed-circuit television, and videotapes have provided alternatives to personal or direct observation (Boone and Stech 1970; Irwin and Nickles 1970; Moore and Mattaliano 1970; Schultz 1972). There has been an increasing trend for the use of audio and videotape (VTR) recordings in supervision of clinical management sessions. 
Audiotape use in clinical settings has been studied by Boone and Prescott (1972). Student clinicians have used audiotapes to listen to their clinical session and evaluate themselves regarding their clinical performance (Boone and Prescott 1972). Audiotape confrontation provides a useful and needed device for on-going self-evaluation by practicing clinicians. Audiotape recorders are readily available to most speech clinicians and thus may be employed at no additional cost and with a minimum of additional time expenditure (Boone and Prescott 1972). Since the great majority of events within a speech management session is verbal in type, the audiotape playback will enable the clinician to recognize the sequence of verbal events within the segment of management to be analyzed (Boone and Prescott 1972).

Using a videotape replay (VTR) for observations the clinical supervisors may view the tape with the clinician and comment at the time the behavior is observed rather than interrupting the management session (Irwin and Nickles 1970). Additionally, Boone and Stech (1970) enumerated six advantages of videotape observation: (1) immediate and continuing re-usable playback, (2) clear pictures with natural lighting, (3) instant correction by retaping, (4) mobility of equipment, (5) stop-frame capability and, (6) preservation of the intervention sessions as long as needed. The supervisor can focus the clinician's attention on the client's behavior as well as the clinician's 
behavior and make comments regarding the management session. (Oratio 1977). Various authors have commented on the use of videotapes of the clinical management sessions. Baldes, Goings, Herbold, Jeffrey, Wheeler, and Freilinger (1975) noted the usefulness of VTR as an aid in recording clinician's work when there is more than one supervisor responsible for evaluation of a student. Both supervisors have the opportunity of viewing the same clinician-client interaction through the use of VTR. Their opinions and comments regarding the student clinician would then have a common base for the feedback. Boone and Stech (1970) reported whenever the audio and video groups in their study were compared on basic change measures employed, there were no significant differences found between the two groups. In other words, both audiotape and videotape could be used to measure behavior change in a clinical session. However, an analysis on a comparison between audiotape and videotape recordings of the same session revealed that an average of 15 to 20 percent of the events contained in the management session are nonverbal and consequently are missed from audiotape scoring. With videotape confrontation the clinician receives the verbal feedback of his clinical session as well as the important nonverbal information (gesture, posture, etc.). In Boone and Prescott's (1972) opinion, videotape seems to provide all the information that an audiotape does, plus the important information relative to nonverbal behaviors. 
Efficient use of time was also discussed with respect to VIR use. Brown (1967) noted the single most important asset of the supervisor is time and the university must provide enough time for the supervisor to do a competent job. The individual supervisor must spend enough time with each student to make supervision effective and not merely "lip service." The extended use of VTR increases this service to the student. Schubert and Laird (1974) suggested that quality supervision takes a great deal of time and energy. Unfortunately the amount of time spent directly supervising trainees is a minimal aspect of the job description for many speech pathologists (Culatta et al. 1975). VTR makes it possible for the student to function quite independently, freeing the instructor for other duties (Kunze 1967).

Decker (1975) stated that an observation technique as valuable as VTR appears to be, must be investigated in various methodological situations. He thought that VTR may distort the way a subject is viewed. Camera angles, lighting etc. may distort the observation being made. Contrary to this idea, studies of the visual observational accuracy, acoustic observational accuracy, and clinical perceptual accuracy using VTR resulted in high reliability and validity in the use of VTR (Irwin and Nickles 1970). Boone and Prescott (1972) have been researching the use of VTR as a clinical training procedure and have found very 
positive results using videotape. They employed VTR as a training procedure for their interactional analyses. A more detailed account of the Boone-Prescott Interactional Analysis System (Boone and Prescott 1972) will be discussed later in this chapter. As indicated by previous discussion, VTR is playing an effective and increasing role in the supervisory feedback of clinical management sessions.

\section{FEEDBACK}

Feedback (comments and critiques of student clinician performance), including verbal conferences and written reports, provides the clinician with information relating to the effectiveness and success of clinical interaction (Payne and Koller 1974). Geoffrey (1973) surveyed the methods being used to assess clinical behavior of student speech pathologists in 111 certified training programs in speech pathology. Three supervisory techniques, i.e., rating scale, written critique, and verbal critique were polled by means of a check list. This check list provided for a general discription of usage of each method according to the observation setting and frequency of supervision.

\section{Verbal Feedback}

Geoffrey (1973) stated verbal feedback or critique is used extensively in all observational settings including direct in-the-room observation, behind one-way mirror observation and audio and videotape recordings. 
Written Feedback

Written feedback is also utilized but to a lesser extent (Geoffrey 1973). As mentioned previously, written feedback takes the form of lengthy comments, or the use of an evaluation form.

Interactional analysis is a system of written feedback utilizing a type of evaluation form. It allows the supervisor and/or clinician to record objectively, the observed clinical behavior for immediate analysis or analysis at a later time (Schubert and Laird 1974). These behavioral events may be recorded utilizing direct observation, audiotape or videotape recordings. Kunze (1967) listed advantages for the use of behavioral event recording: (1) data are preserved which are lost when only impressions are noted, (2) preserved data can be considered in relation to other behaviors emitted at other times, (3) when impressions are recorded, a conclusion is made on the basis of the one behavioral event just observed or on a sequence of events, and (4) behavioral events are objective records and therefore cannot be distorted by observer bias. The use of behavioral event recording is a prominent factor in the systems of interactional analysis.

\section{INTERACTIONAL ANALYSIS SYSTEMS}

According to Simon and Bowyer (1967) there are just over 80 interaction systems available for quantifying and 
analyzing communication within educational, psychological, and speech pathology settings. Amidon and Hough (1967) stated interactional analysis began in the classroom setting as a method for quantitatively and qualitatively recording verbal interactions. Refinements have taken place over the years and various categorical systems have evolved.

Flanders (1965) developed a 10-category system for quantifying both indirect and direct teacher behavior. Blumberg (1970) based his 15-category system on the earlier Flander's model. The use of interactional analysis in speech pathology has been applied since its early inception. Numerous models have been developed in speech pathology, which are unique to the type of interactionswich occur in the speech pathology setting.

Johnson (1969) utilized a 40-category multidimensional scoring system for observing and analyzing a speech pathology clinical process. Both the verbal and nonverbal events (such as gestures, etc.) were codified as clinical transactions. Johnson believed that a multitude of categories within the system allowed for detailed data analysis. Boone and Goldberg (1969) used a 10-category system to study the acquisition of behavioral principles through videotape self-confrontation. This system used a numerical coding of each behavior that occurred. For example, a number 2 (Model and Instruction) was placed on the recording sheet for every clinician instruction observed. This study 
eventually led to the 10-category Boone-Prescott Interactional Analysis System (Boone and Prescott 1972 ).

Schubert and Miner (1972) developed the Analysis of the Behavior of the Clinician System (ABC System). This numerical coding system was very similar to the BoonePrescott System, but used 12 categories and a 3-second interval recording for describing the behavioral events. In this system the observer records a number corresponding to the specific interaction which occurred during each 3 seconds (Schubert and Miner 1972). The ABC System has been used to investigate clinical behavior and to assist in training student clinicians in speech pathology (Clare 1975). Schubert, Miner, and Till (1973) revised the $A B C$ System and have found this system to be reliable in the recording of sessions in articulation and language management.

Conover (1974) developed the Conover Analysis System which uses letter codings corresponding to certain behaviors. It is an event-based rather than a time intervalbased system, i.e., a letter code is recorded as each behavioral event takes place. For example, a clinician model or instruction would be recorded as an M (Model). Her categories included 7 clinician-centered and 4 clientcentered categories.

Grandstaff (1974) developed an ll-category system which included 9 clinician-centered categories and 
2 client-centered categories. According to Oratio (1977) this system has shown to be effective in discerning and discriminating clinical behaviors among various groups of clinicians.

Kaplan and Dreyer (1974) adapted a number of already existing systems into a multidimensional system used to analyze both verbal and nonverbal behavior. They adapted their system for recording specific facial and gestural responses.

Each of the reviewed systems uses various categories. They quantify different types of behavioral events and utilize a slightly different means of scoring. All of them can be used for the purposes of observation and analysis and all yield valuable data for helping speech clinicians modify their own, as well as their client's, behavior (Oratio 1977). This review will focus on the BoonePrescott Interactional Analysis System (Boone and Prescott 1972 ).

The Boone-Prescott Interactional Analysis System was originally developed by Stech (1969) for use in a study by Boone and Goldberg (1969). Prescott (1970) expanded the original 10 categories to 19. He believed this revised system provides a methodology for a more specific description of the clinical process. This Prescott System includes 12 clinician-centered categories and 7 clientcentered behavior categories. Further research by Boone 
and Prescott (1972) led to a modification of the 19category system. The revised system is comprised of 5 clinician-centered categories and 5 client-centered categories (see Appendix A). According to Boone and Prescott (1972) ongoing research using their analysis system has proven to be quite reliable. The Boone-Prescott System has been used in both videotaped and direct (Iive) observations.

\section{IIVE (DIRECT) OBSERVATION VS.}

DELAYED VTR OBSERVATION

Boone and Prescott (1972) noted their analysis system is widely used in direct observation of clinical sessions and indirect observation with the use of videotapes. However, the literature revealed a lack of direct comparison between live and videotaped observation. Conflicting evidence regarding both has been noted. Cooper and Thompson (1971) suggested VTR may increase the observational skills of supervisors, clinicians, and clients. Irwin and Nickles (1970) stated observational techniques such as videotaping may be used to obtain more information and insight than from live observations. Prather (1967) noted it is possible to obtain information and objectivity from VTR that are simply not possible with direct observation alone. 
Likewise, Brookshire, Nichols, Kreuger, and Redmond (1978) contended more information can be gathered from VTR because one can stop and replay segments. To study this, Brookshire et al. (1978) shortened their Clinical Interactional Analysis System (CIAS) from 39 categories to 13 categories to make it easier for direct observation. They stated observers who used CIAS in direct observations recorded an average of 30 percent of all the events which occurred in interactions, whereas observers who performed VTR observations recorded a greater percentage of events. Direct observation was thus suggested to be less accurate than VTR.

Not alI researchers stated VTR observation was preferential. Moore and Mattaliano's (1970) research indicated an increasing use of VTR to record observations, but added that VTR would not eliminate direct observation. This last statement had little justification but appeared to be based on the authors' subjective view that possible direct viewing was more accurate than videotape. Similarly, Jarvis (1973) found VTR required more time than direct observation, as well as being more expensive. He believed the audio and video aspects of VTR may not pick up all the subtle behavioral aspects. Luft and Bemis (1970) studied the reliability among four raters of a live observation and found a relatively high coefficient of .834. They also studied reliability among four raters of a VTR 
observation and found a reliability coefficient of .457 . These data suggested that VTR was not as accurate as Iive observation. No comparison was made, however, using the same VTR and direct observational sample. Billeaud (1973) researched the opinions of teachers on the use of VTR. Although no statistical data is available, the faculty generally indicated their feeling that VTR's were at least as effective as on-the-spot observations, but they did not believe VTR could replace direct observation of teaching sessions.

Schubert and Aitchison (1975) questioned five hundred supervisors and found 67 percent used videotapes in a supervisory procedure and 61 percent used direct observations. No comparison regarding the efficacy of one system over the other was given. O'Neill and Peterson (1964) attempted to evaluate the quality or relative effectiveness of television versus personal observations. They required their observers to make only television observations and then drew their conclusions on the basis of individual opinions. They stated it was difficult to quantify the results, but the consensus of opinion of both the supervisors and observers, was that their television viewing was as effective as personal observations. 
CONCLUSIONS

Boone and Prescott (1972), Schubert et al. (1973), Conover (1974), Clare (1975), and Underwood (1979) suggested a continuing need for methods to supervise and evaluate the clinical speech management process. The interactional analysis systems which have been developed as techniques for the objective description of behavioral interaction between clinician and clients have been effective in recording the interactions.

The suggestion by O'Neill and Peterson (1964) that videotape observations are as effective as direct personal observations seems to be the closest available research comparing live and videotaped observations. There has been minimal research comparing live (direct) observation of the clinical process with observation of a videotape replay of the clinical process. There is a need for this kind of information in order to determine whether a videotape observation of the clinical process provides the same observational results as a direct observation of the clinical process. This information could be used to increase the quantity and quality of the supervisory process in clinical settings. 
CHAPTER III

METHODS

SUBJECTS

The subjects for this study consisted of 11 student clinicians ( 5 undergraduate and 6 graduate) and their respective clients enrolled for clinical practicum at Portland State University Speech and Hearing Sciences Clinic. Each student clinician had completed at least 25 hours of directed clinical observation. The clinical practicums included in this study were two clinics:

(1) Articulation and Language Clinic and, (2) Urban Ianguage Clinic. Clients of each respective clinician were enrolled for clinical management of an articulation and/or language disorder. Some of the clinicians had two clients (hereinafter labeled $a$ and $b$ ) hence, the clinician/client interactional dyads observed in this study numbered fifteen. This study was replicated in two phases (see Procedures) therefore the actual number of clinician/client interactional dyads was thirty. Each subject met the same client for clinical management at a regularly scheduled clinic time. The student clinicians and clients signed an informed consent form (see Appendix B) which permitted their inclusion in this study. 


\section{INSTRUMENTATION}

Raw data were collected utilizing the Boone-Prescott Interactional Analysis System (Boone and Prescott 1972). This learning theory-based system uses numerical codings for types of clinical behavior with a vertical Iine recording (see Appendix C). It provides 5 cliniciancentered categories and 5 client-centered categories (see Appendix A). Session analyses were recorded on a Speech and Hearing Therapy Session Scoring Form (see Appendix D), which not only summarized the total number of events for each category, but also listed the number of certain specific behavioral sequences. Individual category calculations could also be used in various ratios to determine the percentage of correct responses, incorrect responses, good evaluatives, bad evaluatives, inappropriate responses, direct control (by the clinician) and socialization (by both the clinician and client).

The equipment used in this investigation included omni-directional dynamic microphones (Model 635A) (see Appendix E) which were connected via audio connections to the videotape recorder (Model AV 3650) (see Appendix F). The videotape used was a standard one-half inch Sony brand. 


\section{INVESTIGATOR}

The investigator was a student in the Speech and Hearing Sciences Masters Program at Portland State University and in the second year of a two-year graduate program.

\section{Investigator Training}

This investigator was trained in observation and analysis using the Boone-Prescott Interactional Analysis System by a clinical supervisor who holds the National Certificate of Clinical Competence in Speech-Ianguage Pathology. Under the direction of the clinical supervisor, the investigator performed Boone-Prescott Analyses on ten, 5-minute videotaped sessions. Upon completion of these analyses to the satisfaction of the clinical supervisor, the investigator compiled data which underwent an interjudge reliability examination.

\section{Reliability of the Investigator}

The analyses data from two judges and the investigator were used in the interjudge reliability examination of the Boone-Prescott Interactional Analysis System. The two judges, clinical supervisors in the Portland State University Speech and Hearing Clinic, were skilled in interactional analysis, having used one or more of these systems to evaluate interactions on approximately 30 clinical sessions per term for the past four years. Five 
l-minute videotaped samples were randomly selected from clinical tape files and were dubbed onto a master videotape for use in the interjudge reliability examination. The master tape was presented independently to the investigator and judges for interactional analysis. The categories for each analysis completed by the coders were compared for percentage of agreement using the Spearman Rank-Order Correlation Coefficient ( $\mathrm{RHO}$ ) for each pair of judges across the trail data. The interjudge correlation coefficients for each of the videotaped samples were .80, .86, .95, 1.00, and .96 between the investigator and judge number one and $.93, .90, .92,1.00$, and 1.00 between the investigator and judge number two. These data indicated a high degree of similarity between the independent scoring of the examiner and judges, therefore yielding very high interjudge reliabilities. In adition, two weeks following the interjudge procedure, the investigator reanalyzed the sample tapes and reached a .97 correlation coefficient intrajudge (test/retest) reliability.

\section{PROCEDURES}

Half the subjects (Set 1), randomly selected, were observed using direct (live) and videotaped covert observation (without clinician/client awareness of observation). The other half of the subjects (Set 2) were observed using direct (live) and videotaped overt observation (clinician/ 
client aware of observation). On a different day, additional observations were performed. Set 1 were observed using direct (live) and videotaped overt observation and Set 2 were observed using direct (live) and videotaped covert observation. The overt and covert element was used because traditional observation of students does take both the overt and covert form of observation. These elements, however, were not analyzed separately from the live and VTR observations.

\section{Test Setting}

All sessions were videotaped and observed with the clinician/client in 5 by 7 feet clinic rooms located in the Speech and Hearing Sciences Department, Neuberger Hall, Portland State University. The rooms were equipped with a table and chairs and a microphone which was connected via an audio connection to the videotape recorder located in an adjacent observation room. The observation rooms were equipped with a one-way mirror and audio connection which permitted the investigator to observe and record each session (see Figure 1). 
Clinic Room

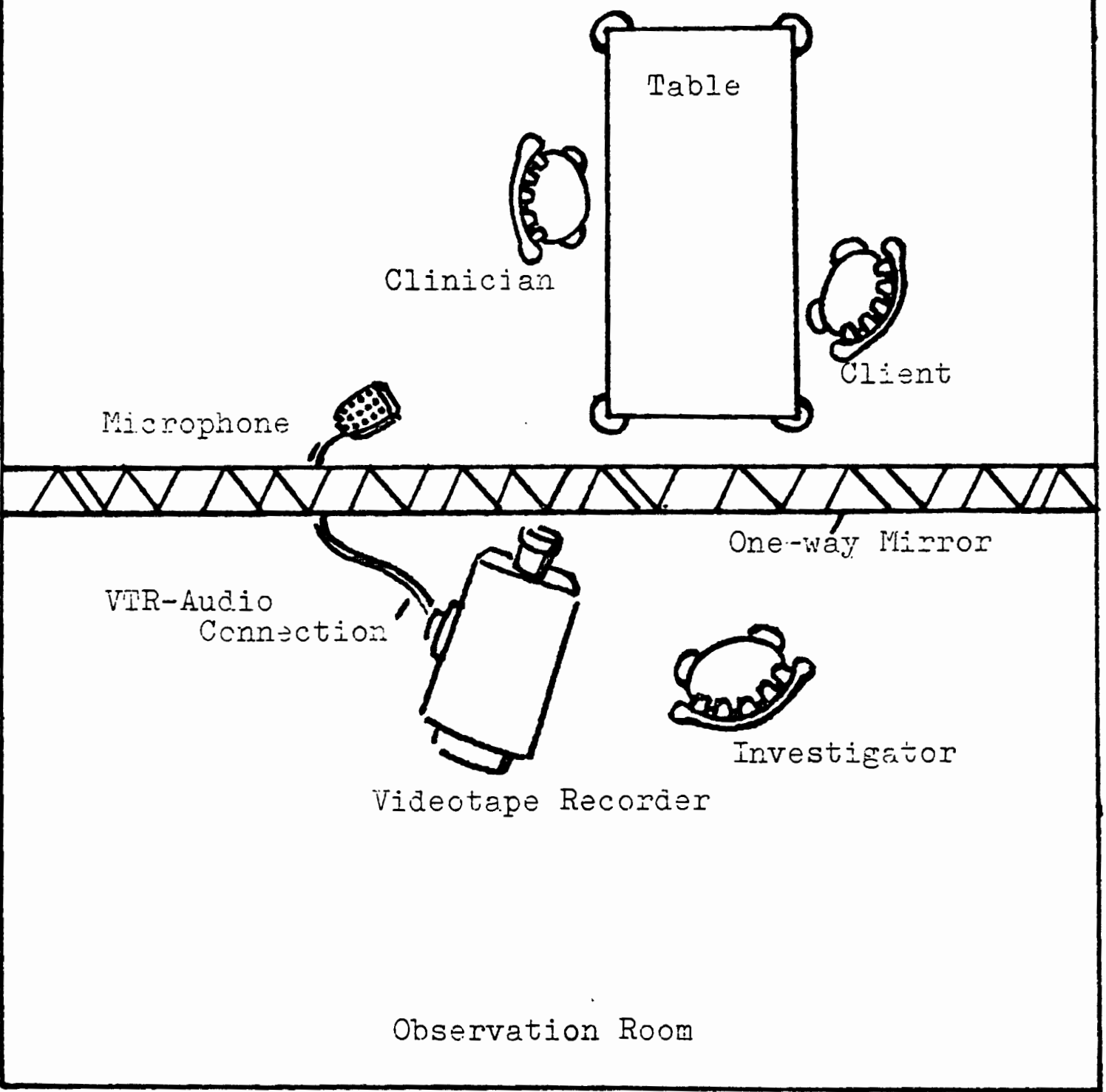

Figure 1. Schtmetic aidgren of the observationclinic room setting. 
Behavior Recording

Behaviors were recorded using a vertical numerical coding system. In other words, as each interaction was observed it was recorded on the recording sheet beneath the preceding behavior in columnar style (see Appendix C). Verbal responses were recorded in "sentence units" indicating that each statement by the clinician or client was denoted by one numerical code (Golper 1976). The clinician repetition of the client's response and the clinician use of client's name were recorded under the number 1 (Explain, Describe) category. Since the BoonePrescott (1972) System does not provide a category for direct control or authority whereby the clinician brings the client's attention back to the task and/or inhibits client nontherapy behavior, this investigator recorded those events under the number I (Explain, Describe) category. A multiple stimulus unit, i.e., request for naming of sequence pictures, or counting objects was recorded as a single number 2 (Model, Instruction) followed by a number 6 or number 7 (Correct or Incorrect Response). Any request for an evaluation, i.e., clinician asks "Was that correct?" was recorded as a number 2 (Model, Instruction). If the clinician were to say, "Super! You did a nice job! Good Work! " in response to a correct utterance by the client, these were rated as three separate positive reinforcements by the clinician or number 3's (Good 
Evaluative). The investigator recorded all clinician extraneous verbalizations, e.g., "um," "alright," "okay" under the number 5 (Neutral, Social) category because those responses were not considered either reinforcing nor necessary to the remediation process (Carnese 1977). Any inattention to the task by the client was recorded as a number 8 (Inappropriate and Social). Any evaluation by the client, called for by clinician or spontaneous by client, was recorded under a number 9 or 10 (Good or Bad SelfEvaluative).

\section{Mode of Recording}

The investigator observed a random 5-minute section of the clinician/client dyad of each subject and recorded the interactions using the Boone-Prescott Interactional Analysis System. The identical 5-minute section of the session was videotaped simultaneously. After each session the tracking sheet (see Appendix C) was marked with the subject number, placed in a large manila envelope and placed in the file cabinet of the clinical supervisor.

\section{Covert Observations}

In the covert observations, the investigator followed the methods described above (Mode of Recording) without the clinicians' knowledge. To ensure a covert recording, certain precautions were taken. As a matter of clinical procedure, each clinician was instructed to sign out a 
microphone from the office and install it in their clinic room for each session during the term. This would ensure that clinicians would not see any new equipment (specifically the microphone) within their clinic room on days when an observation was made. The investigator entered the observation room through a separate passageway after the clinical session had begun, so as not to provide any prior information to the clinician that an observation was being performed.

\section{Overt Observation}

In the overt observations, the investigator followed the methods described above (Mode of Recording) and informed the clinician that an observation and videotaping would be performed during that specific clinical session.

\section{Test Sessions}

Subject dyads $1,2 a, 2 b, 3,4 a, 4 b$, and 5 were first observed covertly, then overtly on a different day, during the first three weeks of clinical management. Subject dyads $6,7,8,9 a, 9 b, 10,11 a$, and $11 b$ were observed overtly, then covertly on a different day, during the first three weeks of clinical management. Order effects of covert/overt conditions were counterbalanced by having a replication set of the observations performed during the last three weeks of clinical management, providing a waiting period of three weeks between sets. During the replication 
set Subjects $1,2 a, 2 b, 3,4 a, 4 b$, and 5 were first observed overtly, then covertly on a different day and Subjects $6,7,8,9 a, 9 b, 10,11 a$, and $11 b$ were first observed covertly, then overtly on a different day (see Table I):

\section{TABLE I}

ORDER EFFECTS OF COVERT/OVERT CONDITIONS

\begin{tabular}{|c|c|c|c|}
\hline & \multirow{2}{*}{ Subjects } & \multicolumn{2}{|c|}{$\begin{array}{c}\text { Type of } \\
\text { Observation }\end{array}$} \\
\hline & & Day I & Day 2 \\
\hline 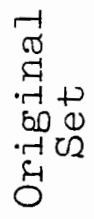 & $\begin{array}{l}1,2 a, 2 b, 3,4 a, 4 b, 5 \\
6,7,8,9 a, 9 b, 10,11 a, 11 b\end{array}$ & $\begin{array}{l}\text { Covert } \\
\text { Overt }\end{array}$ & $\begin{array}{l}\text { Overt } \\
\text { Covert }\end{array}$ \\
\hline 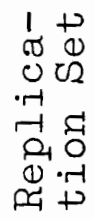 & $\begin{array}{l}1,2 a, 2 b, 3,4 a, 4 b, 5 \\
6,7,8,9 a, 9 b, 10,11 a, 11 b\end{array}$ & $\begin{array}{l}\text { Overt } \\
\text { Covert }\end{array}$ & $\begin{array}{l}\text { Covert } \\
\text { Overt }\end{array}$ \\
\hline
\end{tabular}

Two weeks after the completion of data collection, the investigator viewed each videotaped session straight through and performed an analysis of each session. These analyses were then marked with subject number. At the completion of the analysis of all videotaped sessions, the investigator transferred all the data to the BoonePrescott Ten Category Speech and Hearing Therapy Session Scoring Forms (see Appendix D). Each form was coded with data regarding Subject number, overt/covert and direct/VTR information. 


\section{DATA ANALYSIS}

Data analysis included a comparison between live observation results and videotaped observation results. Each observation was compared using a Spearman Rank-Order Correlation ( $\mathrm{RHO})$. Each category was compared using a 2-tailed $\mathrm{t}$-test for dependent means in order to determine significant differences in observations between the direct observations and VTR observations. In addition, the Pearson Product Moment Correlation ( $r$ ) was performed on each individual category in order to determine the relationship correlation between live and VTR observation for each individual category (Siegel 1956).

Additionally, the means of the total numbers of each behavioral category, clinician total, client total, and observation total were illustrated in table form. 
CHAPTER IV

RESULTS AND DISCUSSION

\section{RESUITS}

The question investigated in this research was: Are the observational results the same for videotape as for a live session? The Boone-Prescott Interactional Analysis System (Boone and Prescott 1972) was used to record the interactions of clinicians and their respective clients in Articulation and Language Clinic and Urban Language CIinic at Portland State University. The data were analyzed in three different ways as a means to answer the research question. The resultant data were the basis for the statistical analysis and the following results.

The Spearman Rank-Order Correlation Coefficient (RHO) was utilized to determine the correlation between the results of each live analysis compared to videotaped analysis. The average of each of the lo-category counts recorded in live sessions and videotaped sessions were ranked and compared (see Table II). The resultant Spearman RHO was .99 , a very high positive correlation which is significant beyond the .02 level of confidence. This suggests the observational results for videotaped and live sessions are the same. 
TABLE II

SPEARMAN RHO RANKINGS FOR LIVE AND VIDEOTAPED OBSERVATIONS

\begin{tabular}{rrr}
\hline Categories & $\begin{array}{c}\overline{\mathrm{X}} \\
\text { Live }\end{array}$ & $\begin{array}{c}\overline{\mathrm{Y}} \\
\text { VTR }\end{array}$ \\
\hline 1 & 16.66 & 15.83 \\
2 & 44.30 & 51.53 \\
3 & 18.90 & 17.93 \\
4 & 2.70 & 2.32 \\
5 & 10.36 & 10.73 \\
6 & 26.23 & 26.86 \\
7 & 4.50 & 3.30 \\
8 & 5.06 & 4.93 \\
9 & .06 & .06 \\
10 & .00 & .00 \\
Clinician total & 96.01 & 98.05 \\
Client total & 37.48 & 35.62 \\
Observation total & 133.08 & 134.23 \\
\hline
\end{tabular}

In addition a Spearman Rank-Order Correlation Coefficient (RHO) was performed on the observational results of each individual subject (see Table III). The resulting Spearman RHO's were very high, (.82 to .99; significant beyond the .02 level of confidence) further supporting the statement that observational results for videotaped and live sessions are the same. 


\section{TABLE III}

SPEARMAN RANK-ORDER CORRELATION (RHO) OF INDIVIDUAL SUBJECTS

\begin{tabular}{cc||cc}
\hline \hline Subject & RHO & Subject & RHO \\
\hline 1 & .94 & 16 & .99 \\
2 & .99 & 17 & .99 \\
3 & .99 & 18 & .99 \\
4 & .99 & 19 & .99 \\
5 & .99 & 20 & .99 \\
6 & .99 & 21 & .88 \\
7 & .99 & 22 & .96 \\
8 & .99 & 23 & .96 \\
9 & .99 & 24 & .99 \\
10 & .99 & 25 & .82 \\
11 & .99 & 26 & .99 \\
12 & .99 & 27 & .98 \\
13 & .99 & 28 & .99 \\
14 & .99 & 30 & .99 \\
15 & & 29 & \\
\hline
\end{tabular}

Pearson Product Moment Correlations ( $r$ ) revealed positive coefficients for all categories (see Table IV). This suggests a very high correlation reflecting a very dependable relationship, i.e., VTR observations and live observations yield essentially the same observational data. A 2-tailed $t$-test for dependent means was performed on each of the Boone-Prescott System's 10 categories (see Table V). 
TABLE IV

PEARSON PRODUCT MOMENT CORRELATION $(r)$

Category $r$

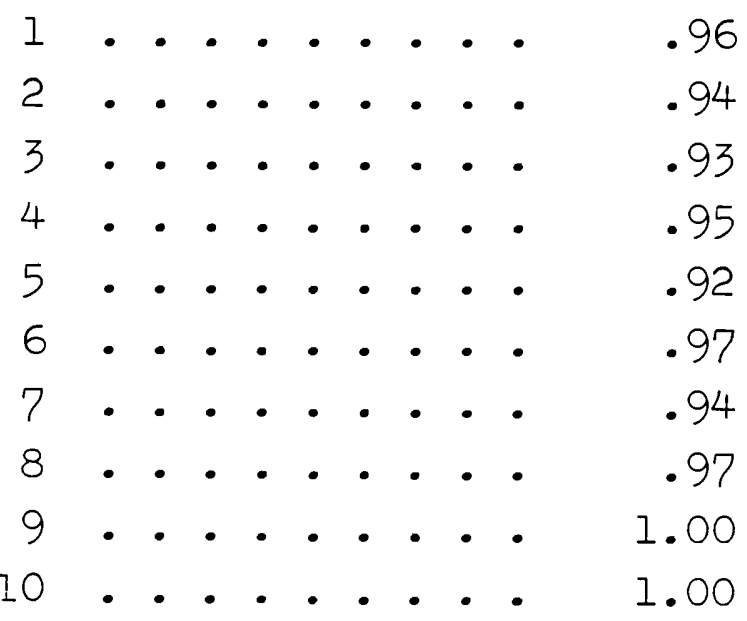

TABIE V

TWO-TAILED $t$-TEST FOR DEPENDENT MEANS

Category

$\underline{t}^{*}$

1

1.28

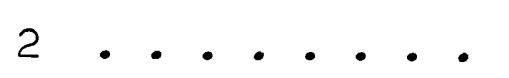

$7.35 * *$

3

1.43

4

1.46

$5 \cdot \cdot \cdot \cdot \cdot \cdot$

.59

6 . . . . . .

1.35

7

$2.42 * *$

8

.45

9 ・. • . •. .

.00

10

.00

${ }^{*}$ Critical value of $\underline{t}=1.697$.

**Significant at .05 level of confidence. 
The two groups differed significantly at the .05 level of confidence in 2 of the 10 categories. Of the two groups, Category 2, Clinician Instruction and Model, displayed the greatest variance from the critical value of $\underline{t}$ (statistically significant beyond the .05 level of confidence) i.e., more observations were recorded for this category from the VTR method of viewing. Category 7, Client Incorrect Response, varied slightly over the critical value of $\underline{t}$, i.e., the observer recorded more responses from the direct observation. For the remainder of the categories, no significant differences were found at the .05 level of confidence.

\section{ISCUSS ION}

The statistical procedure employing the Spearman Rank-Order Correlation (RHO) between live and VTR observations revealed a very high correlation between the results obtained from direct (live) observation and VTR observations. As noted in Table III, 28/30 comparisons ranked at .94 or higher. It appears this study has shown that one may use videotape in lieu of direct observation and can be confident the observations will reflect an accurate account of the clinical session. Further supporting these results, a finer distinction between the results of VTR and direct (live) observations was performed. An inter-category comparison correlating live and VTR observations was made 
using the Pearson Product Moment Correlation ( $r$ ). As noted in Table IV the majority of the correlations of observable results between VTR and direct (live) observation in each of the ten categories was .92 or higher.

The results of the 2-tailed $t$-test for dependent means between live and VTR observations in each of the 10 categories are displayed in Table II. Category 2 (Model and Instruction) showed the greatest variance from the critical value of $t$ at the .05 level of confidence, in the direction of VTR observation. This author believes this to be partially the result of the ambiguity of recording clinician responses, i.e., a clinician may explain (Category 1) a point to the client and then expect the client to also use the explanation as a model or stimulus (Category 2). The observer must then decide whether the event is recorded as a 1 or a 2 . This author further believes a more detailed description of which event will be recorded under which number needs to be firmly established by each individual before utilizing this procedure. This ambiguity may also be revealed as a difference between the VTR and direct observation since the VTR observation was performed after a considerable length of time had expired after the original observation and initial training period of the observer. The time span would lead to the observer inadvertently recording events under a different category than he had originally decided upon. The significant level 
of difference may also indicate the observer sees more clinician responses through the use of VTR. This could be due to the fact that the pressure on the observer of recording responses from the VTR is less than direct observation, i.e., the VTR observation is performed at a time convenient to the observer.

Category 7 (Incorrect Response) varied minimally from the critical value of $t$ at the .05 level of confidence in the direction of live observations. The author believes this may be an artifact of the acoustic distortion influence of the observation monitoring system, coupled with any ambiant noise present in the observation room, i.e., people talking. The observer may perceive a client's auditory response as incorrect when it may have been a correct response. The direct audio connection to the VTR produced very clear acoustic transfer and thus there would be less margin of acoustic error when observing the videotape replay.

Table VI shows the category ratio of agreement between live and VTR observations. The ratio represents the number of observations for each category for live observations to those for VTR observations. The average ratio of agreement between live and VTR within the clinician-centered categories is 1.00:.94. The average ratio of agreement between live and VTR within the clientcentered categories is 1.00:1.02. This may be due to the 
fact that although there are 5 categories for both client and clinician, categories 9 and 10 (Good and Bad Selfevaluatives) are less often encountered in clinical sessions. Therefore the observer is concerned primarily with only 3 client-centered categories. This results in fewer observer decisions to make when recording client responses. Further, the remaining 3 categories are so explicitly defined as to the appropriate response there is less ambiguity in recording responses. It also appears the clinician has more responses during the session and the observer therefore has a greater probability of missing some of these responses during the direct observation, but may pick these up when viewing the VTR. This may be due to the probability of fewer ambiant distractions to the observer when viewing the VTR. As well, the client responses often are anticipated by the observer and therefore the observer is more likely to record events accurately in both VTR and direct viewing situations. This observation tends to support the Boone and Prescott decision to reduce the number of categories from 19 to 10. 
TABLE VI

\section{CATEGORY RATIO OF AGREEMENT}

BETWEEN LIVE AND VTR

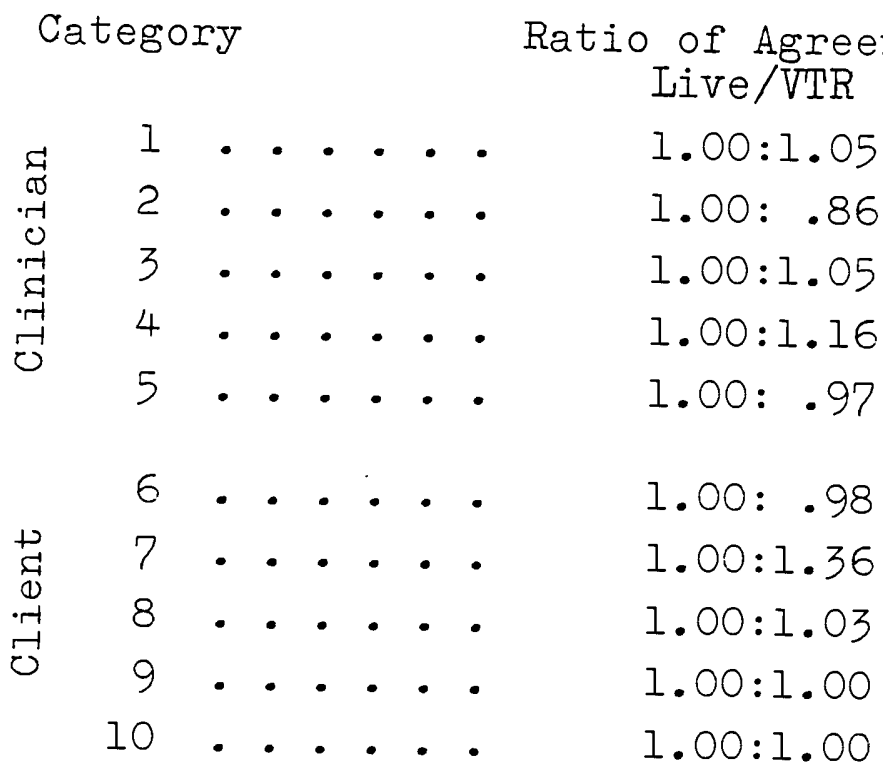

As noted in Table VII the total number of observable events recorded was slightly greater for VTR, i.e., out of 30 cases 21 had more results for VTR observation as compared to 9 out of 30 cases for direct observation. This suggests the observer tends to see more behavior while viewing the VTR than when observing the clinical sessions directly. 
TABLE VII

TOTAL NUMBER OF OBSERVABLE RESUITS FOR VTR AND LIVE

\begin{tabular}{|c|c|c|c|c|c|}
\hline Subject & Live & VTR & Subject & Live & VTR \\
\hline 1 & 97 & 104 & 16 & 141 & 153 \\
\hline 2 & 134 & 134 & 17 & 147 & 147 \\
\hline 3 & 71 & 75 & 18 & 107 & 116 \\
\hline 4 & 111 & 115 & 19 & 121 & 127 \\
\hline 5 & 134 & 141 & 20 & 142 & 147 \\
\hline 6 & 156 & 169 & 21 & 71 & 75 \\
\hline 7 & 148 & 148 & 22 & 131 & 147 \\
\hline 8 & 68 & 70 & 23 & 162 & 162 \\
\hline 9 & 123 & 127 & 24 & 130 & 128 \\
\hline 10 & 241 & 230 & 25 & 105 & 107 \\
\hline 11 & 77 & 74 & 26 & 141 & 168 \\
\hline 12 & 91 & 98 & 27 & 156 & 180 \\
\hline 13 & 131 & 134 & 28 & 173 & 174 \\
\hline 14 & 181 & 176 & 29 & 131 & 130 \\
\hline 15 & 142 & 145 & 30 & 104 & 117 \\
\hline
\end{tabular}

The results of this study do not support the statement that more information and insight can be obtained through the use of VTR observation (Prather 1967; Irwin and Nickles 1970; Cooper and Thompson 1971). They did not state whether they viewed the VTR with a stop and start procedure or with a straight through viewing as was done in 
this research. Therefore a stop and start VTR viewing procedure may increase the number of observable results for VTR observations as stated by the Brookshire et al. (1978) study.

This author preferred the VTR observations because he was able to view them at a time convenient for him. In addition, there were no distractions such as people interrupting him or sound equipment failing and thus the analyses of the sessions were performed with less distraction. Nevertheless the videotapes were not always clearly recorded. Although the results show that VIR and Iive (direct) observations are equally as accurate, this author must agree with Decker (1975) who stated camera angles, lighting etc. may distort the way a subject is viewed. The equipment used in this study was inadequate for an artifactfree research study. The bulky machinery was difficult to move around in the small observation rooms and often the resulting VTR was less than desirable. The camera lens was designed specifically for low-light situations but had too great a focal length which eliminated observation of the complete clinic setting.

Irwin and Nickles (1970) reported high reliability and validity using VTR and this study supports that view. As the research equipment between the two studies was not closely matched however, this study cannot support their statement regarding visual observation accuracy. 


\title{
CHAPTER V
}

\section{SUMTIARY AND IMPLICATIONS}

\author{
SUMIIARY
}

This research examined the validity of videotaped analyses of clinical sessions in comparison to direct (live) observations. The subjects were 11 student clinicians and their respective clients, enrolled Fall Term, 1979, in Portland State University's Speech and Hearing Sciences Articulation and Ianguage and Urban Language Clinics. The Boone-Prescott Interactional Analysis System (Boone and Prescott 1972), a numerically coded system, was used to record clinician/client interactions. Data were obtained for a randomly selected 5-minute period from each of 30 clinical sessions.

Results of this research indicate the videotape analyses of clinical sessions correlated very highly with the direct (live) observation analyses of the same clinical sessions. This suggests the observational results are the same for videotape as for a live session. Individual behavioral category comparisons indicated two statistically significant differences at the .05 level of confidence between the two settings. Category 2 (Instruction and Model) showed that more observations were recorded for this 
category from the VTR method of viewing. Category 7 (Incorrect Response) indicated the observer recorded more observations using direct observation. The present research procedures do not support statements by Prather (1967), Irwin and Nickles (1970), Cooper and Thompson (1971), and Brookshire, Nicholas, Krueger, and Redmond (1978) which suggested that more information and insight can be obtained through the use of VTR observation. Results indicate one gets essentially the same results from VTR observation as from direct observation.

\section{RESEARCH IMPIICATIONS}

There are a number of implications for further studies, as indicated by this research. One would be to replicate the present research project utilizing more compact VTR equipment and a low focal length wide angle camera lens. A replication of this study which utilizes a stop and start (reviewing) method of VTR observation may give some indication that VTR does provide more observational results than does direct observation. A replication of this study utilizing a different interactional analysis system would also be of interest because it may provide data that suggests a different interactional analysis system is more accurate or less accurate than the BoonePrescott Interactional Analysis System. 
Research comparing overt and covert observations would be of particular benefit because both these methods are frequently employed in observation and evaluation of students in training centers. This project could be broken into overt-covert live observation and overt-covert VTR observation, which would provide a variation on the results of this study.

An interesting project would be to train a parent of a child enrolled in management, to use an interactional analysis system and then to compare the results of clinical observations between the parent and a trained speech pathology student. This may show the trained student tends to focus on different aspects of the clinical session than would the parent.

A study observing VTR's of many clinical dyads and formulating specific descriptions of all the various behaviors observed would help to decrease the ambiguity of some of the categories of the Boone-Prescott Interactional Analysis System.

Further studies might include observation of reactions to the VTR between a child versus adult client. Additionally the same type of study could include beginning and experienced clinicians reactions to either direct observation or VTR observation.

Because of the significant difference of Category 2 and Category 7, a project which focused on the analysis 
of only clinician or only client responses might lead to a change in the elements which are included in the various categories.

\section{CLINICAL IMPLICATIONS}

Results of this research indicate that clinical supervision might be enhanced through the increased use of videotaped clinical sessions. Videotaping would be of particular benefit to the student clinician who would like feedback on a particular clinical session especially if the supervisor is unable to directly observe that specific session. Supervisors could videotape clinical sessions that would be of particular interest to colleagues and other students with the assurance that the videotape would provide essentially the same information as the direct observation. When clinic session times coincide with each other student clinicians often miss the opportunity to observe their fellow student clinicians. Videotaping various clinical sessions would provide opportunity for student colleagues to observe and learn from each other. 


\section{BIBIIOGRAPHY}

AMIDON, E. J. and HOUGH, E. G. Interactional Analyses: Theory, Research and Application. Reading: AddisonWesley (1967).

ANDERSON, J. Supervision of the clinical process in speech pathology: Issues and practices. Short course presented at the American Speech and Hearing Association Convention, Las Vegas (1974).

BAIDES, R. A., GOINGS, R., HERBOID, D. D. , JEFFREY, R., WHEELER, G., and FREILINGER, J. J. Report of the task force on supervision of student speech clinicians. Department of Public Instruction, Special Education Division, Des Moines (1975).

BILIEAUD, F. P. The Use of Videotape Recordings to Teach Clinical Skills (Evaluations and Remediation) in the Field of Communicative Disorders. Lafayette: University of S. W. Louisiana (1973).

BOONE, D. R. and GOLDBERG, A. An Experimental Study of the Clinical Acquisition of Behavioral Principles of

Video-tape Self-Confrontation. Final Report. Project No. 4071, Grant No. OEG 8-071319-2814, U.S. Department of Health, Education and Welfare, Division of Research, Bureau of Education for Handicapped, Office of Education (1969).

, and PRESCOTT, T. Content and sequence analysis. ASHA, $14,58-62$ (1972).

and STECH, E. I. The Development of Clinical Skills in Speech Pathology by Audiotape and Videotape Self-Confrontation. Final Report. Project No. 1381, Grant No. OEG 9-071318-2814, U.S. Department of Health, Education and Welfare, Division of Research, Bureau of Education for the Handicapped, Office of Education (1970).

BLUMBERG, A. A system for analyzing supervisor-teacher interaction. IN A. Simon and G. Boyer (eds.)

Mirrors for Behavior. Philadelphia: Research for Better Schools Inc. (1970). 
BROOKSHIRE, R. H. , NICHOLAS, I. S., KRUEGER, K. M. , and REDMOND, $K$. The clinical interaction analysis system: a system for observational recording of aphasia treatment. J. Speech Hearing Dis., 43(4) 437-47 (1978).

BROWN, E. I. A universities approach to improving supervision. ASHA, 9, 476-9 (1967).

BUTLER, K. W. Videotaped self-confrontation. ISHSS, 4(3), 162-7 (1974).

CARNESE, T. M. A Comparison of the Clinician-Client Interactions in Urban Language Clinic and Stuttering Clinic. M.S. thesis, Portland State University (1975).

CIARE, S. K. A Study of Student Clinicians' Behaviors in Response to Feedback from the Analysis of Behaviors of the Clinician ( $A B C$ ) System. M.S. thesis, Portland State University (1975).

CONOVER, H. Conover Analysis System. Paper presented at the American Speech and Hearing Association Convention, Las Vegas (1974).

COOPER, E. B. and THOMPSON, M. P. Accuracy of stuttering perceptions following self-observation through videore,cordings. J.Comm. Dis., 4, 119-125 (1971).

CULATTA, R., COLUCCI, S., and WIGGINS, E. Clinical supervisors and trainees: two views of a process. ASHA, $17(3), 152-57$ (1975).

DARLEY, F. Clinical training for full-time clinical service: a neglected obligation. ASHA, 11, 143-8 (1969).

DECKER, W. D. Videotape as an Observational Technique: A Critique. ERIC Reference ED 103536 (1975).

FLANDERS, N. A. Interaction Analysis in the Classroom: A Manual for Observers. Ann Arbor: University of Michigan (1965).

GEOFFREY, V. C. Report on Supervisory Practices in Speech and Hearing. Report, University of Maryland (1973).

GOLPER, I. D. The Efficacy of Teaching Interaction Analysis to Students in Speech Pathology. M.S. substantiated paper, Portland State University (1976). 
GRANDSTAFF, H. L. A Comparison of Clinical Behaviors of Untrained, Moderately Trained and Trained Speech Clinicians During Articulation Therapy. Ph.D. dissertation, University of Cincinnati (1974).

HALFOND, M. Clinical supervision: a stepchild in training. ASHA, $6,441-4$ (1964).

HALLER, R. Supervisor's criteria for evaluation of student's performance in clinical observation. ASHA, 9, 479-81 (1967).

IRWIN, R. B. and NICKIES, A. A. The use of audio-visual films in supervised observation. ASHA, 12, 363-7 $(1970)$.

JARVIS, D. K. Video-tape Recording as a Supplement to InPerson Supervision. ERIC Reference ED 073695 (1973).

JOHNSON, T. S. The Development of a Multi-dimensional Scoring System for Observing the Clinical Process in Speech Pathology. Ph.D. dissertation, University of Kansas (1969).

KAPLAN, N. R. and DREYER, D. E. The effect of selfawareness training on student speech pathologistclient relationship. J. Comm. Dis., 7, 329-42 (1974).

KLEVANS, D. F. and VOLZ, H. B. Development of a clinical evaluation procedure. ASHA, 16, 489-91 (1974).

KUNZE, L. H. Program for training in behavioral observations. ASHA, 9, 473-6 (1967).

LUFT, M. and BEMIS, K. Videotape Techniques for Establishing Inter-rater Reliability. Department of Health, Education and Welfare, Bureau of Research, Office of Education (1970).

MINER, A. Standard for quality supervision of clinical practicums. ASHA, 9, 471-2 (1967).

MOORE, J. J. and MATTALIANO, A. P. Clinical Supervision: A Short Description. West Hartford Public Schools, Conn. (1970).

O'NEILL, J. J. and PETERSON, H. A. The use of closed circuit television in a clinical speech training program. ASHA, 6, 445-7 (1964). 
ORATIO, A. R. Supervision in Speech Pathology: A Handbook for Supervisors and Clinicians. Baltimore: University Park Press (1977).

PAYNE, P. D. and KOLLER, E. E. Teaching and Supervising Student Clinicians Using Closed Circuit Television. Paper presented at the American Speech and Hearing Association Convention, Las Vegas (1974).

PRATHER, E. M. An approach to clinical supervision. ASHA, $9,472-3$ (1967).

PRESCOTT, T. E. The Development of a Methodology for Describing Speech Therapy. Ph.D. dissertation, University of Denver (1970).

SCHUBERT, G. W. and AITCHISON, C. A profile of clinical supervisors in college and university speech and hearing training programs. A.SHA, 17, 440-7 (1975).

and IAIRD, B. A. Length of Time Necessary to Obtain a Representative Sample of Clinician-Client Interaction. Paper presented at the American Speech and Hearing Association Convention, Las Vegas (1974).

, and MINER, A. Modification of Flanders' Interaction Analysis Categories for Observation in Speech Therapy. Paper presented at the American Speech and Hearing Association Convention, San Francisco (1972).

, MINER, A. I., and TILI, J.A. The Analysis of Behavior of Clinicians (ABC) System. University of North Dakota Press (1973).

SCHUITZ, M. D. An Analysis of Clinical Behavior in Speech Hearing. Englewood Cliffs: Prentice-Hall, Inc. (1972).

SIEGEL, S. Nonparametric Statistics for the Behavioral Sciences. New York: McGraw-Hill (1956).

SIMON, A. and BOYER, E. Mirrors for Behavior: An Anthology of Observation Instruments. Philadelphia Research for Better Schools, Inc. (1967).

STECH, E. I. An Empirical Study of Video-tape SelfConfrontation, Self-Evaluation and Behavior Change in Speech Therapist Trainees. Ph.D dissertation, University of Denver (1969).

UNDERWOOD, J. K. Personal correspondence. University of Northern Colorado (1979). 
VAN RIPER, C. Supervision of clinical practice. ASHA, 7, 75-7 (1965).

VILIARREAI, J. Seminar on Guidelines for Supervision of Clinical Practicum. Washington, D.C. (1964).

WARD, I. and WEBSTER, E. The training of clinical personnel: issues in conceptualization. ASHA, 7, 38-40 (1965). 
APPENDIX A

\section{BOONE-PRESCOTT CONTENT AND \\ SEQUENCE ANALYSIS SYSTEM}

NUMBER TITLE

1 Explain, Describe

2 Model, Instruction

3 Good Evaluative

4 Bad Evaluative

5 Neutral or Social

6 Correct Response

7 Incorrect Response

8 Inappropriate and Social (irrelevant behavior

9 Good self-evaluative

10 Bad self-evaluative

\section{DESCR IPTION}

Clinician describes or explains the specific goals or procedures of the session.

Clinician specifies client behavior by direct modeling or by a specific request.

Clinician evaluates client response and indicates approval verbally or nonverbally.

Clinician evaluates client response and indicates disapproval verbally or nonverbally.

Clinician engages in behavior that is not management goal oriented.

Client makes a response which is correct in terms of the stated management goals, or the clinician stimulus.

Client makes a response that is incorrect according to the stated management goals or clinician request.

Client makes a response or engages in social conversation that is not appropriate to the management goals.

Client indicates awareness of his own correct response.

Client indicates awareness of his own incorrect response. 
APPENDIX B

\section{INFORMED CONSENT}

I hereby agree (to serve/let serve) as a subject in the research project on the Comparison of Live and Videotaped Observations conducted by John Hanlan, Graduate student, Speech and Hearing Sciences, Portland State University.

I understand that the study may involve direct observation and/or videotaping of the Speech and Hearing Sciences clinical management session with which I am connected.

I understand that there are no possible risks to me associated with this study and it will not interfere with my regular duty as a speech/language clinic participant.

It has been explained to me that the purpose of this study is to compare the observational results from direct observation to those observational results from videotaped observation.

I may not receive any direct benefit from participating in this study, but my participation may help to increase knowledge which may benefit others in the future.

John Hanlan has offered to answer any questions I may have about the study and what is required of me in the study.

I understand that I am free to withdraw from participation in this study at any time without jeopardizing my relationship with Portland State University and the Department of Speech Communication, Speech and Hearing Sciences Program. 
I have read and understand the foregoing information. Signature of Participant or Guardian/Parent Date

If you experience problems that are the result of your participation in this study, please contact Richard Streeter, Office of Graduate Studies and Research, 105 Neuberger Hall, Portland State University, 229-3423 
APPENDIX C

SAMPLE TRACK ING SHEET

Subject__ I Session_1

2
6
3
2
6
3
2
6
2
6
2
7
4
1
2
6
3
9
2
7
10
8
5
1
2
6
3 


\section{APPENDIX D}

TEN-CATEGORY SPEECH AND HEARING THERAPY SESSION SCORING FORM

\section{Clinician: \\ Client: \\ Date:}

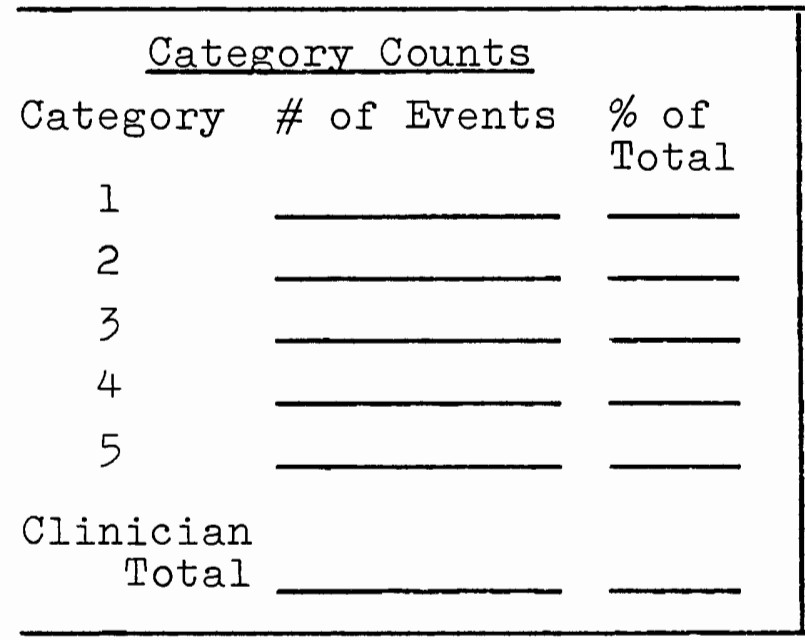

Sequence Counts

Sequence \# of Events
$6 / 3$
$7 / 4$
$8 / 1,2$

Clinician/

Client Total

Responses per minute
Category Counts Category \# of Events \% of Total

6

7

8

9

10

Client

Total
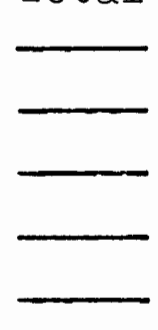
Therapy Evaluation

A Good Session

Therapist Effective

Client Effective Progress

Client Effectiveness Measures
No

Yes

$1--2--3--4--5--6--7--8--9$

$1--2--3--4--5--6--7--8--9$

$1--2--3--4--5--6--7--8--9$ $=$

Comments 


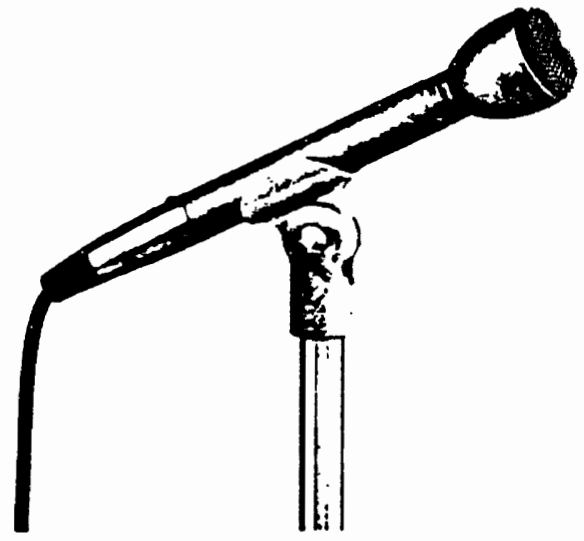

OESCRIPTION AND APPLICATIONS

The E.V model 635A is a dynamic, omnidirectional microphone designed for exacting professional applications, and is ideally suited for film production, recording, FM, AM, and TV broadcasting, and for the more demand. ing $P A$ applications.

The model $635 \mathrm{~A}$ is supplied with the model $312 \mathrm{~A}$ stand adapter. The non-reflecting fawn beige micomatte finish is ideal for "on camera" use. The high output level and low sensitivity to mechanical shock make it excellent for interviews, for pass around use in audience participation or for hand-held use by vocalists.

This microphone features the exclusive non-metallic Electro-Voice Acoustalloy diaphragm which permits very smooth response over a wide frequency range, and withstands high humidity and temperature extremes, corrosive effects of salt air, and severe mechanical shocks. It is practically indestructible with normal use.

A four-stage pop and dust filter insures completely popfree performance and virtually eliminates the need for an external windscreen for outdoor use.

Intermal shock absorber effectively reduces pickup of cable and other noise generated by external contact.

\section{SPECIFICATIONS}

Element:

Frequency response:

Polar Pattern:

Impedence:

Output level:
Dynamic 80 - 13,000 Hz Omnidirectional Low (150 ohms) $-55 \mathrm{~dB}\left(0 \mathrm{~dB}=1 \mathrm{mw} / 10\right.$ dynes $\left./ \mathrm{cm}^{2}\right)$

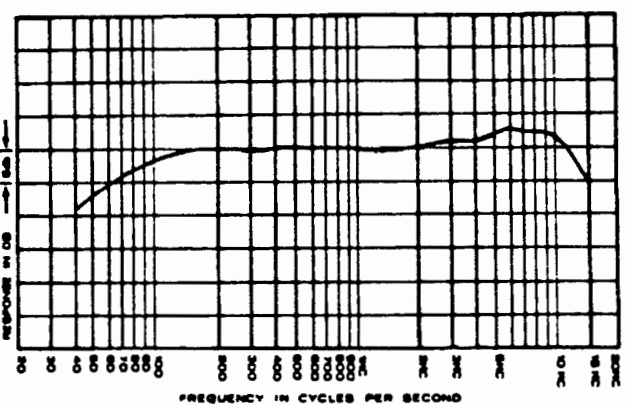

FIGURE 1 - Response Curve

ElA sensitivity rating Diaphragm:

Case material:

Dimensions:

Finish:

Net Weight:

Switch:

Cable:

Accessories Furnished: Optional Accessories:
$-149 \mathrm{~dB}$

Electro-Voice Acoustalloy ${ }^{\circ}$

Steel

$5.15 / 16 "(151 \mathrm{~mm}) 1 . \times 1.13 / 32^{\prime \prime}$

$(36 \mathrm{~mm}) \mathrm{dia}$.

Fawn beige micomatte 6 ounces $(170 \mathrm{~g})$, without cable

None

$15^{\prime}(4.6 \mathrm{~m}), 2$-conductor shielded broadcast type synthetic rubber-jacketed with Switchcraft A3F connector.

Model 312A Stand Adapter Model 307 Shockmount

Model 314E Windscreen

Mudel 340 Security Clamp Model 342 Security Stud Mount

\section{ARCHITECTS' AND ENGINEERS' SPECIFICATIONS}

The microphone shall be an Electro. Voice model 635A or equivalent. The microphone shall be an omnidirectional dynamic type with wide-range response uniform from 80 to $13,000 \mathrm{~Hz}$. It shall have a non-metallic Acoustalloy diaphragm and a four-stage pop filter and magnetic shield to prevent dust and magnetic particles from reaching the diaphragm. The impedance shall be such that the microphone will match 50, 150, and $250 \mathrm{ohm}$ inputs. The line shall be balanced to ground and phased.

The output level shall be $-55 \mathrm{~dB}$ with $0 \mathrm{~dB}$ equalling 1 $\mathrm{mw} / 10$ dynes $/ \mathrm{cm}^{2}$. EIA sensitivity tating shall be -149 dB. The magnetic circuit shall be a nonwelded circuit and employ Alnico $V$ and Armco magnetic iron. The case shall be made of steel. 
The microphone shall have a maximum diameter of $1.13 / 32 "(36 \mathrm{~mm})$, and a length of $5.15 / 16 "(151 \mathrm{~mm})$, and a weight, without cable, of 6 or. (170g). Finish shall be non-reflecting fawn beige micomatte. A 15 foot $(4.6 \mathrm{~m}), 2$ conductor shielded, synthetic rubber-jacketed, broadcast type cable shall be provided with a Switchcraft A3F or equivalent connector installed. The microphone shall have a built-in connector similas or equivalent to the Switchcraft A3M. The microphone shall include a stand couplet with a 5/8".-27 thread. The Electro-Voice Model 635A is specified.

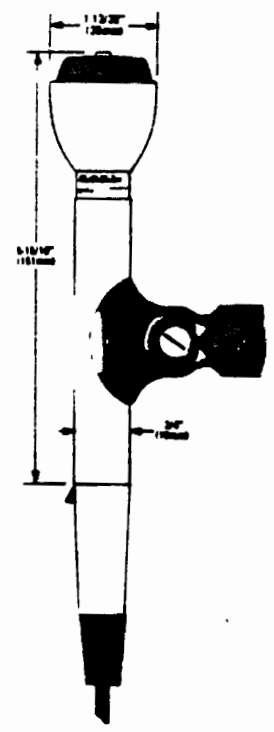

FIGURE 2 - Dimmeion

\section{WARRANTY (Limited) -}

Electro.Voice Professional Dynamic Broadcast, Recording, and Sound Reinforcement Microphones are guaranteed unconditionally against malfunction from any cause for a period of two years from date of original purchase. Also, every Electro-Voice microphone is guaran. teed for the life of the microphone against malfunction due to defects in workmanship and materiais. If such mal. function occurs, microphone will be repaired or replaced (at our option) without charge for materials or labor if deliveted prepaid to the proper Electro-Voice service facility. Unit will be returned prepaid. Warranty does not cover finish, appearance items, cables, cable connectors, or switches and lifetime warranty does not cover malfunction due to abuse or operation at other than specified conditions. Repair by other than Electro-Voice or its authorized service agencies will void this guarantee.

For correct shipping address, instructions on return of Electro-Voice products for repair, and locations of authorized service agencies, please write: Service Department, Electra-Voice, Inc., 600 Cecil Street, Buchanan, Michigan 49107 (Phone 616/695-6831).

Electro-Voice also maintains complete facilities for nonwarranty service of $\mathrm{E} \cdot \mathrm{V}$ products.

Specifications subject to change without notice.

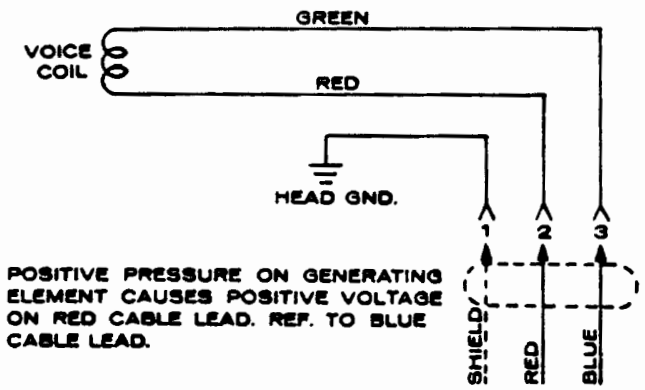

FIGURE 3 - Wiring Disgram 


\section{APPENDIX F}

\section{LIST OF INSTRUNENTS USED IN THE STUDY}

Videotape Replay . . . . Sony-Matic AV-3650

reel-to-reel recorder

Camera . . . . . . Sony Camera and Panasonic Camera Monitor

Lens... - . . . TVC Vidicon Zoom $25 \mathrm{~mm}$ to $100 \mathrm{~mm} \mathrm{~F} 1.8$

Monitor . . . . . . Setchell-Carlson T.V. Monitor Model 2100 S.D. 